national database and treated with bDMARD between June 2008 and July 2020. Demographic, clinical and laboratorial data (including 25-hydroxyvitamin $\mathrm{D}$ [25-OHvitD]) at baseline and disease activity measures at 6 and 12 months of treatment with the first bDMARD were collected. Correlations between variables were evaluated by Spearman rank test, Mann-Whitney $U$ test was used to the comparison analysis between groups and univariate logistic regression was used in the prediction analysis.

Results: A total of 195 SpA patients were included: 103 (52.8\%) females, 47 (24.1\%) smokers and 91 (46.7\%) HLA-B27 positive; 139 (71.3\%) had Ankylosing Spondylitis, 18 (9.2\%) had Inflammatory Bowel Disease Associated SpA and 38 $(19.5 \%)$ had Undifferentiated SpA. At the time of the first bDMARD, the mean age was 43.5 years $( \pm 9.6)$ and the median disease duration was 12.4 years $(0.7$ 52.7). The mean ASDAS-CPR (Ankylosing Spondylitis Disease Activity Score with C-reactive protein) was $3.9( \pm 0.8)$ and, in addition, $61(31.3 \%)$ patients had 25-OHvitD levels below $30 \mathrm{ng} / \mathrm{mL}$ and $12(6.2 \%)$ had 25-OHvitD levels below $20 \mathrm{ng} / \mathrm{mL}$. Fifty-three patients $(27.2 \%)$ were taking NSAIDs (nonsteroidal anti-inflammatory drugs), 77 (39.5\%) were under csDMARDs (conventional synthetic disease-modifying antirheumatic drugs). Adalimumab (56\%) and golimumab (33.3\%) were the most frequently initiated bDMARDs in the first line.

There were no statistically significant correlations between baseline 25-OHvitD levels and ASDAS-CRP at $6(r=0.031 ; p=0.714)$ and 12 months $(r=0.035$; $\mathrm{p}=0.672$ ) of bDMARD.

In the subgroup analysis: there were no statistically significant differences in the response to bDMARD at 6 and 12 months evaluated by ASDAS response and ASAS 20, 40 and 70 responses according to the baseline 25-OHvitD levels (25-OHvitD $<20 \mathrm{ng} / \mathrm{mL}$ vs $\geq 20 \mathrm{ng} / \mathrm{mL}$; 25 -OHvitD $<30 \mathrm{ng} / \mathrm{mL}$ vs $\geq 30 \mathrm{ng} / \mathrm{mL}$ ); and there were no statistically significant differences in the baseline $25-\mathrm{OHvitD}$ levels at baseline according to the response to bDMARD at 6 and 12 months of bDMARD (ASDAS: no response vs clinically important improvement or major improvement; ASAS 20: no response vs response).

In the line of these previous results, baseline 25-OHvitD levels did not predict the ASDAS response at 6 (OR 0.97 [0.95-1.00], 95\% Cl) or 12 (OR 0.98 [0.95-1.01], $95 \% \mathrm{Cl}$ ) months of bDMARD.

Conclusion: Despite some data that suggest that lower levels of 25-OHvitD may be associated with higher disease activity in SpA, our results failed to demonstrate that the baseline 25-OHvitD levels can be related or predict treatment response after 6 and/or 12 months of therapy with the first bDMARD in real-life SpA patients.

Disclosure of Interests: None declared

DOI: 10.1136/annrheumdis-2021-eular.997

\section{AB0836 DIAGNOSIS VALUE OF INTERLEUKIN 17 IN SPONDYLOARTHRITIS}

L. Kharrat ${ }^{1}$, M. Slouma ${ }^{1}$, A. Tezeghdenti ${ }^{2}$, W. Dkhili ${ }^{2}$, R. Dhahri ${ }^{1}$, E. Ghazouani ${ }^{2}$, I. Gharsallah ${ }^{1}$, L. Metoui ${ }^{1}$, B. Louzir ${ }^{1}{ }^{1}$ Military Hospital of Instruction of Tunis, Rheumatology, Tunis, Tunisia; ${ }^{2}$ Military Hospital of Instruction of Tunis, Immunology, Tunis, Tunisia

Background: Interleukin 17 (IL-17) is pro-inflammatory cytokine that plays a crucial role in spondyloarthritis via the Th17/IL-17 axis. (1)

Objectives: We aimed to study the diagnosis value of IL-17 serum in spondyloarthritis.

Methods: We conducted a case-control study, including 104 subjects divided into 2 groups:

-G1: 52 patients meeting the Assessment of SpondyloArthritis International Society (ASAS) criteria for spondyloarthritis (SA)

-G2: 52 healthy controls matched for age and sex.

The IL-17 level was measured using Enzyme-linked immunosorbent assay (ELISA).

We performed a ROC analysis and computed the air under the curve (AUC) at IL-17 to assess the ability of IL-17 to diagnose SA.

Statistical analysis was performed using "IBM SPSS Statistics" software version 25.

Results: Eighty per cent of the patients were men $(n=41)$. The mean age was $44.96 \pm 13.09$ years. The mean age at the onset of the disease was $35.07 \pm$ 12.66 years. The disease duration was $9.25 \pm 8.09$ years. Axial radiographic spondyloarthritis and peripheral involvement were found in $53.8 \%(n=28)$ and $44.2 \%(n=23)$ of cases, respectively. Psoriasis was noted in $46 \%$ of cases $(n=24)$. The mean ASDAS-CRP was $3.21 \pm 1.64$.

IL-17 level was significantly higher in patients compared to healthy controls $(92.76 \pm 71.85 \mathrm{pg} / \mathrm{mL}$ and $2.67 \pm 9.01 \mathrm{pg} / \mathrm{mL}$, respectively, $\mathrm{p}<0.0001)$.

As shown in Figure 1, the AUC value to distinguish between spondyloarthritis and healthy control was 0.987 ( $p<0.0001$ ). IL-17 cut-off was $13.79 \mathrm{pg} / \mathrm{mL}$ (Sensibility $=94.2 \%$, specificity $=98.1 \%$ ).

Conclusion: According to previous studies, our study showed that serum IL-17 level is significantly higher in SA patients compared to healthy controls (2).

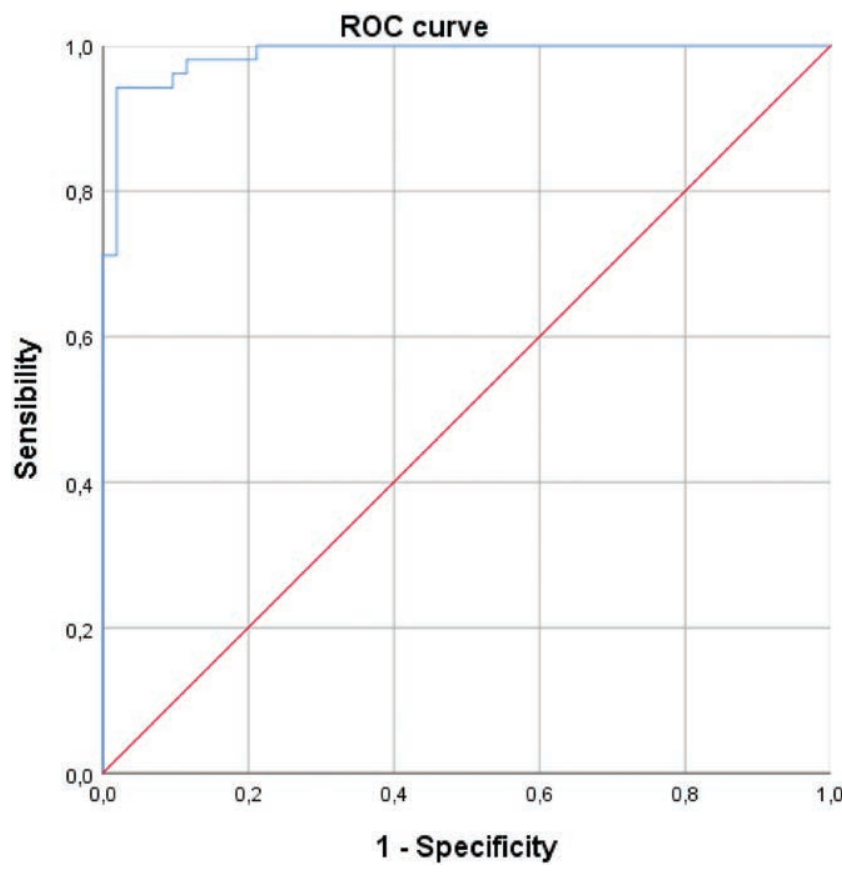

Figure 1. AUC at IL-17 between SA patients and healthy controls $0.987(p<0.0001)$

Interestingly, IL-17 was able to distinguish between SA patients and healthy controls with a cut-off of $13.79 \mathrm{pg} / \mathrm{mL}$. This finding suggests that IL-17 may be useful for the diagnosis of SA.

REFERENCES:

[1] Ruiz de Morales JMG, Puig L, Daudén E, Cañete JD, Pablos JL, Martín AO et al. Critical role of interleukin (IL)-17 in inflammatory and immune disorders: An updated review of the evidence focusing in controversies. Autoimmun Rev. janv 2020;19(1):102429.

[2] Chen W-S, Chang Y-S, Lin K-C, Lai C-C, Wang S-H, Hsiao K-H, et al. Association of serum interleukin-17 and interleukin-23 levels with disease activity in Chinese patients with ankylosing spondylitis. J Chin Med Assoc. juill 2012;75(7):303-8.

Disclosure of Interests: None declared

DOI: 10.1136/annrheumdis-2021-eular.1020

\section{AB0837 $\quad$ SERUM YKL-40 LEVELS IN PATIENTS WITH EARLY RHEUMATOID ARTHRITIS: RELATION TO DISEASE ACTIVITY AND JOINT DESTRUCTION}

E. Aleksandrova ${ }^{1}$, A. Novikov ${ }^{1}$, E. Luchikhina ${ }^{2}$, D. Karateev ${ }^{2}$, G. Lukina ${ }^{3}$. ${ }^{1}$ Moscow Clinical Scientific Center n.a. A.S. Loginov, Clinical Immunology, Moscow, Russian Federation; ${ }^{2}$ Regional Research and Clinical Institute (MONIKI), Department of Rheumatology, Moscow, Russian Federation; ${ }^{3}$ Moscow Clinical Scientific Center n.a.A.S. Loginov, Department of Rheumatology, Moscow, Russian Federation

Background: YKL-40 (chitinase-3-like 1 protein, human cartilage glycoprotein 39) is one of the major proteins secreted locally in the arthritic joint by activated macrophages, chondrocytes, synoviocytes and neutrophils, YKL-40 an important marker for inflammation, cartilage remodelling and synovial hyperplasia is recognized as a possible auto-antigen in rheumatoid arthritis (RA).

Objectives: The aims of the study were to determine the serum level of YKL-40 in early RA and investigate his relationship with biomarkers of disease activity and joint destruction.

Methods: We studied 22 patients with early RA (ACR/EULAR 2010 classification criteria); 4 males, 18 females; median and interquartile range (25th -75 th percentile) of age 55,0 (43,0-64,0) years, disease duration $7,0(5,0-11,0)$ months, DAS28 4,9 (4,3-5,8); 86\% IgM rheumatoid factor (IgM RF) +; 91\% anti-cyclic citrullinated peptide antibody (anti-CCP) +. All patients were treated with methotrexate (MTX). Three (14\%) patients received low oral doses of steroids and intra-articular injections. The control group included 22 healthy donors $(\mathrm{HC})$. Radiographs were scored according to the van der Heijde-modified Sharp score. YKL-40, matrix metalloproteinase-3 (MMP-3), anti-CCP were detected using commercially available enzyme-linked immunosorbent assays (ELISA). The serum levels of IgM RF, C-reactive protein (CRP), serum amyloid A (SAA) were measured by immunonephelometry. 